\title{
Desenvolvimento de plantas de girassol sob diferentes condições de fornecimento de água
}

\section{Development of sunflower plants under different conditions of water supply}

\author{
Carla Cristina Dutra ${ }^{1,4 *}$ Eber Augusto Ferreira do Prado ${ }^{2,3}$; \\ Leandro Ramão Paim ${ }^{2,4}$; Silvana de Paula Quintão Scalon ${ }^{5}$
}

\section{Resumo}

\begin{abstract}
A falta ou excesso de água no solo são prejudiciais ao desenvolvimento das plantas. Assim, o objetivo deste trabalho foi avaliar o crescimento de plantas de girassol em diferentes capacidades de retenção de água (CRA). O experimento foi realizado em casa de vegetação, com a variedade de girassol Embrapa $122 / \mathrm{V}-2000$, sob o delineamento experimental em blocos casualizados com quatro tratamentos $(60 \%$ CRA, $80 \%$ CRA, 100\% CRA e condição de alagamento) e quatro repetições. As plantas foram avaliadas semanalmente entre os estádios V6 (caracterizado pela presença de seis folhas com no mínimo 4,0 $\mathrm{cm}$ ) ao R4 (inicio da florescência). Avaliou-se a altura das plantas, diâmetro de caule, teor de clorofila, matéria seca das folhas, do caule, da parte aérea e das raízes, número de folhas, área foliar, e a relação entre a matéria seca da raiz e da parte aérea. Os resultados mostraram que as plantas de girassol apresentaram maior altura e diâmetro de colmo quando submetidas à maior disponibilidade de água. Nos tratamentos com estresse hídrico o aumento do teor de clorofila foi limitado, e nos tratamentos com maior disponibilidade hídrica o teor inicialmente aumentou, mas, nas últimas avaliações decresceu. Apesar da relação raiz/parte aérea ter apresentado maiores valores para o tratamento $60 \%$ da CRA, a área foliar, número de folhas, matéria seca do caule, da raiz, e da folha apresentou menores valores a $60 \%$ da CRA. Portanto, o melhor desenvolvimento dessas plantas foi observado quando submetidas a 80 e $100 \%$ da CRA.
\end{abstract}

Palavras-chave: Ácido abscísico, estresse hídrico, etileno, Helianthus annuus, hipoxia

\begin{abstract}
Usually the lack or excess of water in the soil is harmful to plant development. Therefore, our objective was to evaluate the growth of sunflower plants under different water holding capacities (WHC). Trials were conducted in a greenhouse with plants of the sunflower cultivar Embrapa 122/V-2000. The experimental design was a randomized complete block with four treatments: $60 \%, 80 \%$ and $100 \%$ of WHC and a flooding level with four replications. Plants were evaluated weekly between stages V6 (with six leaves and $4.0 \mathrm{~cm}$ tall) to R4 (flowering). We evaluated the plant height, stem diameter, leaf chlorophyll content, leaves, stems, shoot and root dry matter, number of leaves, leaf area, and the relationship between root and shoot dry matter. The results showed that the sunflower plants had greater

1 Doutoranda do Programa de Pós-Graduação e Agronomia/Produção Vegetal, Faculdade de Ciências Agrárias, FCA, Universidade Federal da Grande Dourados, UFGD, Dourados, MS. E-mail: carlacristina.dutra@gmail.com

2 Mestrando(s) do Programa de Pós-Graduação e Agronomia/Produção Vegetal, FCA, UFGD, Dourados, MS. E-mail: eberprado@, hotmail.com; leandro.r.paim@hotmail.com

3 Bolsista do Conselho Nacional de Desenvolvimento Científico e Tecnológico - CNPq.

4 Bolsista da Coordenação de Aperfeiçoamento de Pessoal de Nível Superior - CAPES.

5 Prof ${ }^{a}$ Dra $^{\mathrm{a}}$. do Programa de Pós-graduação em Agronomia, Produção Vegetal, FCA, UFGD, Dourados, MS. E-mail: silvanascalon@

Autor para correspondência
\end{abstract} ufgd.edu.br 
height and stem diameter when subjected to higher WHC. Under water stress the increased chlorophyll content was limited, and in treatments with high water availability the content initially increased, but decreased in later evaluations. Although the root/shoot ratio of dry matter was observed to be higher for treatment $60 \%$ of WHC, the dry matter of stem, root and leaf, number of leaves and leaf area on $60 \%$ of WHC resulted in smaller values. Therefore, improved development of these plants was observed when exposed to 80 and $100 \%$ of the WHC.

Key words: Abscisic acid, drought stress, ethylene, Helianthus annuus, hypoxia

\section{Introdução}

A cultura do girassol (Helianthus annuus L.) apresenta características agronômicas importantes, como maior resistência à seca, ao frio e ao calor, em comparação à maioria das espécies normalmente cultivadas no Brasil. Graças a estas características, apresenta-se como uma opção nos sistemas de rotação e sucessão de culturas nas regiões produtoras de grãos (EMBRAPA CNPSO, 2000). Porém, a necessidade hídrica do girassol ainda não está bem definida. A porcentagem média de água usada na cultura do girassol é de aproximadamente $20 \%$ durante o estádio vegetativo e $55 \%$ durante o florescimento, restando $25 \%$ para o estádio de enchimento de grãos (FAO, 2002). Suas necessidades hídricas estão entre $500 \mathrm{~mm}$ e $700 \mathrm{~mm}$ de água, sendo estas aumentam com o desenvolvimento da planta, partindo de valores ao redor de 0,5 a $1 \mathrm{~mm} /$ dia no período compreendido entre a semeadura e emergência, atingindo um máximo de 6 a $7 \mathrm{~mm} /$ dia na floração e enchimento de grãos, decrescendo após este período (CARTER, 1978). Geralmente, a fase mais crítica ao déficit hídrico é o período entre 10 a 15 dias antes do início do florescimento e 10 a 15 dias após o final da floração (SFREDO; CAMPOS; SARRUGE, 1984). A maior sensibilidade à seca sobre o conteúdo de óleo ocorre nos dez primeiros dias após o secamento das flores liguladas, sendo essa fase, a mais crítica para sua produção (CASTRO et al., 2006).

As raízes da planta de girassol têm capacidade de extrair até uma profundidade máxima de dois metros aproximadamente $92 \%$ da água disponível da camada de solo (BREMNER; PRESTON; STGROTH, 1986), o que possibilita a sua resistência a curtos períodos de estresse hídrico. A água extraída pelas raízes é aproveitada com baixa eficiência, visto que, sendo que para cada litro de água consumido produz menos de dois gramas de matéria seca. Porém, em condições de déficit hídrico, esta eficiência aumenta em torno de $20 \%$ a $50 \%$ (EMBRAPA CNPSO, 2000).

O sistema radicular é profundo e bem desenvolvido lateralmente, e a capacidade de manutenção da fotossíntese mesmo em condições adversas, permite tolerar curtos períodos de seca, assegurando rendimento em comparação com outras espécies de interesse agronômico conduzidas nestas condições (EMBRAPA CNPSO, 2000).

Em geral, a falta ou excesso de água numa cultura são prejudiciais ao seu desenvolvimento (LEITE; BRIGHENTI; CASTRO, 2005). A determinação das necessidades hídricas das culturas, em seus diferentes estádios de desenvolvimento, é uma etapa importante para o manejo de irrigação (AMORIM NETO; GOMIDE; SEDIYAMA, 1996). O déficit hídrico no solo pode levar a planta ao estresse hídrico, provocando mudanças morfológicas e fisiológicas. A menor disponibilidade hídrica pode levar a redução na expansão celular, redução na área foliar, aumento na abscisão foliar, diminuição da relação entre a biomassa da raiz com a parte aérea, fechamento de estômatos e redução na fotossíntese. Outra condição ambiental que provoca estresse nas plantas é o solo alagado, esta condição leva a falta de oxigênio para as raízes, o que provoca a morte dos tecidos radiculares por favorece a fermentação lática e acidose nas células, podendo também levar a redução na absorção de nutrientes e água por falta de energia (TAIZ; ZEIGER, 2009). 
Os hormônios vegetais, principalmente o etileno e o ácido abscísico (ABA), estão ligados as mudanças morfológicas e fisiológicas nas plantas sob estresse hídrico ou por hipoxia. O nível de ABA aumenta em plantas estressadas por falta de água. Acredita-se que ele estimule o fechamento estomático e diminua a relação raiz/parte aérea, devido a estimular o crescimento da raiz por reduzir a síntese do etileno e diminuir crescimento do caule, também favorece a maior abscisão de folhas (SHARP, 2002). A falta de oxigênio acelera a produção do ACC (1-aminociclopropano-1-ácido carboxílico) que é o precursor do etileno. O ACC é translocado da raiz para a parte aérea e na presença de oxigênio é convertido em etileno. O etileno pode levar ao alongamento caulinar, epinastia, abscisão foliar, senescência e perda de clorofila (TAIZ; ZEIGER, 2009).

Os estudos com diferentes níveis de irrigação para o girassol indicam que o aumento da quantidade de água disponível leva ao acréscimo de parâmetros como altura, matéria seca, matéria seca de capítulo e peso das sementes. Silva et al. (2007) estudaram quatro níveis de lâmina de água $(117,20 ; 350,84$; 428,70 e 522,14 mm) e verificaram maior produção, teor de óleo, e altura de plantas em lâmina de $522,14 \mathrm{~mm}$. Por outro lado, quando em hipoxia, o efeito apresentado é contrário, ocorrendo redução no crescimento de raízes e parte aérea (LETEY; STOLZI; BLANK, 1962).

Neste contexto o trabalho teve por objetivo avaliar o desenvolvimento de plantas de girassol, cultivar EMBRAPA 122, em diferentes condições de capacidade de retenção de água.

\section{Material e Métodos}

O experimento foi realizado em casa de vegetação na Faculdade de Ciências Agrárias da Universidade Federal da Grande Dourados (UFGD) no período compreendido entre os meses de abril a junho de 2010, situada no município de Dourados (2213'16"S, 54¹7'01"W e altitude de $430 \mathrm{~m}$ ), Mato Grosso do Sul, Brasil.
A cultivar de girassol utilizada foi o híbrido Embrapa 122/V-2000. Foram semeadas manualmente quatro sementes por vaso de polietileno com capacidade de 10 litros e estes foram revestidos com saco plástico para minimizar a perda de água por escorrimento. O solo utilizado no estudo pertence à classe Latossolo Vermelho Distroférrico. Cada vaso continha $8,850 \mathrm{Kg}$ de solo seco. A adubação de semeadura foi realizada por meio de solução nutritiva, contendo macro e micronutrientes, e adubação em cobertura com nitrogênio e potássio foi realizada um mês após a semeadura. Estas adubações foram realizadas com base na análise de solo e na exigência da cultura. Após duas semanas realizou-se o desbaste das plantas, deixando-se apenas as duas mais vigorosas por vaso.

O experimento foi esquematizado em delineamento experimental em blocos casualizados com quatro tratamentos (60\% CRA, 80\% CRA, $100 \%$ CRA e condição de alagamento). As doses de água para cada tratamento foram calculadas a partir do nível de $100 \%$ da capacidade de retenção de água (CRA). A determinação da CRA foi realizada em laboratório, em quatro repetições, segundo este procedimento após a homogeneização do substrato retirou-se uma amostra, que foi seca em estufa e pesada, utilizando-se $1 \mathrm{~kg}$ de solo por vaso para a determinação. Nestes vasos adicionouse água até ficar saturado, após o escorrimento do excesso sobrou apenas à água retida (solo úmido), e determinou-se a capacidade de reposição de água pela diferença entre as massas do solo úmido e do solo seco.

As aplicações das doses de água foram iniciadas no estádio fenológico VE (emergência dos cotilédones). $\mathrm{O}$ controle da reposição da perda de água foi realizado através da pesagem dos vasos em balança analógica, sendo a reposição realizada a cada dia com uma proveta graduada em mililitros.

Entre os períodos fenológicos V6 (caracterizado pela presença de seis folhas com no mínimo 4,0 
$\mathrm{cm})$ e R4 (inicio da abertura da inflorescência) foram avaliados por cinco vezes em intervalos de sete dias: altura das plantas (através de uma régua, medindo da base do colo até a inserção da última folha completamente expandida); diâmetro de coleto (medido através de paquímetro) e o teor de clorofila das plantas, determinado em uma folha completamente expandida escolhida ao acaso, em cada parcela, sendo o valor determinado com auxílio do aparelho Chlorophyll Meter SPAD-502, cujo método de medição se da por diferença de densidade ótica entre dois comprimentos de onda, obtendo-se a média por parcela.

No estádio R4 realizou-se o corte das plantas que, posteriormente, foram avaliadas quanto ao número de folhas (NF) e a área foliar (AF), com auxílio do medidor LI-COR modelo LI-3000. e em seguida, secas em estufa para determinação da matéria seca das folhas (MSF), caule (MSC) e parte aérea (MSPA), matéria seca de raiz (MSR), e a relação entre a matéria seca da raiz com a da parte aérea (MSR/MSPA).

As análises de regressão foram realizadas pelo programa computacional, Sistema para Análise de Variância - SISVAR. (FERREIRA, 2000).

\section{Resultados e Discussão}

Os resultados das análises de regressão do número de folhas, área foliar, MSF, MSC, MSR, diâmetro de caule e altura das plantas foram altamente significativas com relação a capacidade de retenção de água (CRA) no solo (Tabelas 1 e 2).

Tabela 1. Valores do teste F e coeficiente de variação $(\mathrm{CV})$ das variáveis da planta de girassol em função de diferentes capacidades de retenção de água - CRA.

\begin{tabular}{cccccc}
\hline $\begin{array}{c}\text { Fonte de } \\
\text { variação }\end{array}$ & $\begin{array}{c}\text { Número de } \\
\text { folhas }\end{array}$ & Área foliar & $\begin{array}{c}\text { Massa seca de } \\
\text { raiz }\end{array}$ & $\begin{array}{c}\text { Massa seca de } \\
\text { folhas }\end{array}$ & $\begin{array}{c}\text { Massa seca de } \\
\text { caule }\end{array}$ \\
\hline CRA & $11,383^{* *}$ & $158,83^{* *}$ & $40,536^{* *}$ & $84,469^{* *}$ & $84,781^{* *}$ \\
CV $(\%)$ & 13,46 & 9,12 & 16,12 & 10,97 & 13,28 \\
\hline
\end{tabular}

** significativo a $1 \%$ de probabilidade pelo teste $\mathrm{F}$.

Fonte: Elaboração dos autores.

Tabela 2. Valores do teste $\mathrm{F}$ e coeficiente de variação $(\mathrm{CV})$ das variáveis das plantas de girassol avaliadas durante $\mathrm{o}$ estádio fenológico V6 ao R4 em função de diferentes capacidades de retenção de água - CRA.

\begin{tabular}{cccc}
\hline Fonte de variação & Diâmetro de caule & Altura de plantas & Clorofila na folha \\
\hline CRA & $92,21^{* *}$ & $159,707^{* *}$ & $1,194^{\text {ns }}$ \\
Tempo & $214,283^{* *}$ & $1741,917^{* *}$ & $41,550^{* *}$ \\
CRA x T & $6,564^{* *}$ & $93,294^{* *}$ & $5,713^{* *}$ \\
CV 1 (\%) & 12,23 & 14,43 & 5,48 \\
CV 2 (\%) & 7,93 & 5,08 & 3,67 \\
\hline
\end{tabular}

** significativo a $1 \%$ de probabilidade pelo teste $\mathrm{F}$. ${ }^{\text {ns }}$ não significativo a $5 \%$ de probabilidade pelo teste $\mathrm{F}$.

Fonte: Elaboração dos autores.

As plantas de girassol apresentaram menor altura quando desenvolvidas em condições de 60 e $80 \%$ da CRA (Figura 1). Corroborando com os resultados de Nezami et al. (2008) que mostraram decréscimo do crescimento das plantas de girassol da cultivar Chernianka onde a disponibilidade de água no solo foi menor e também com os resultados alcançados por Campos et al. (2010), onde a reposição de água 
ao girassol Embrapa 122/V-2000, independente da percentagem, elevou a altura das plantas. Assim como verificado por Silva et al. (2007), que ao estudarem a aplicação de lâminas de água e doses de boro na cultura do girassol nos híbridos Hélio 250 e Hélio 251, afirmam que a altura das plantas sob condições de campo, aumenta linearmente em função da lâmina de água oferecida.

Figura 1. Altura das plantas de girassol em diferentes níveis de capacidade de retenção de água (CRA), em casa de vegetação, durante o estádio fenológico V6 ao R4.

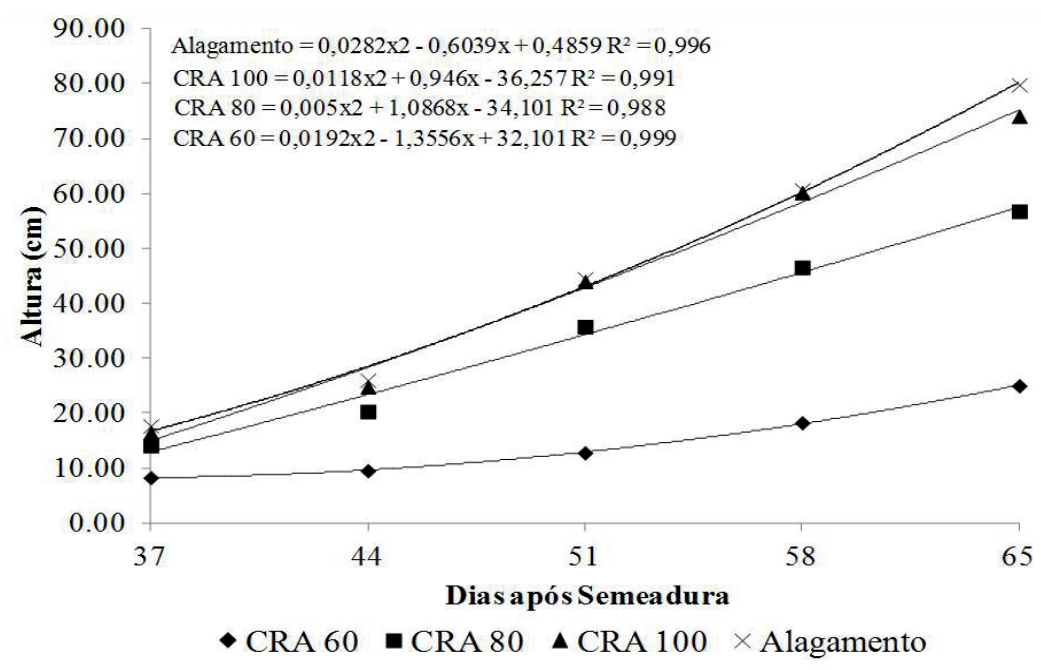

Fonte: Elaboração dos autores.

O decréscimo da altura das plantas pode estar relacionado ao nível de ácido abscísico (ABA) (considerado um hormônio que retarda o crescimento vegetal) que aumenta em plantas estressadas por falta de água (SHARP, 2002). Este ácido é considerado um sinalizador da raiz, promovendo a redução da taxa de transpiração da planta pelo fechamento estomático (TAIZ; ZEIGER, 2004). As mudanças hormonais também influenciam a morfologia e fisiologia das plantas sob estresse hídrico. Durante as fases iniciais do estresse hídrico ocorre à alcalinização da seiva do xilema e maior transporte de ABA para as folhas, que atua nas células-guarda do estômato, modificando o transporte de cátions e ânions, ele provoca efluxo de $\mathrm{K}^{+}$e ânions, e inibição da bomba de prótons $\mathrm{H}^{+}$ através da membrana plasmática, causando saída de água pelo menor potencial osmótico e com isso há fechamento dos estômatos para evitar a perda excessiva de água (TAIZ; ZEIGER, 2009).

As plantas com maior abundância de água (100\% CRA e hipoxia) cresceram mais no sentido apical (Figura 1). O mesmo foi observado por Campos et al. (2010), onde a reposição de $100 \%$ da CRA foi responsável pelo maior crescimento das plantas de girassol.

Apesar do maior crescimento das plantas nos tratamentos com maior disponibilidade de água, estas não atingiram seu desenvolvimento normal, pois as maiores alturas aos 45 dias após a emergência (DAE) ficaram em torno de $27 \mathrm{~cm}$, quando o tamanho esperado seria mais de $100 \mathrm{~cm}$, isso pode ser explicado pelo fato do experimento ter sido desenvolvido em casa de vegetação. Em trabalhos desenvolvidos no campo, foi observado 
por Acosta (2009) altura média de $130 \mathrm{~cm}$ aos 45 DAE quando as plantas de girassol foram cultivadas em área irrigada e, também verificado por Biscaro et al. (2008) que observaram altura média de plantas de $114,7 \mathrm{~cm}$ aos 45 DAE quando cultivadas sob adubação nitrogenada. $\mathrm{O}$ menor crescimento pode ser explicado, em parte, pela atuação do etileno, uma vez que, plantas em condições de hipoxia têm maior produção deste hormônio na parte aérea o que pode causar redução no tamanho da planta, redução no crescimento de folhas, caules e raízes, epinastia, senescência e abscisão foliar, aumento da espessura da base caulinar, formação de raízes adventícias e de aerênquima, bem como hipertrofia de lenticelas dos caules e raízes além da redução da fotossíntese, contribuindo para o menor crescimento (KERBAUY, 2004, TAIZ; ZEIGER, 2009).

As plantas cultivadas com maior disponibilidade hídrica (100\% CRA e hipoxia), apresentaram maior diâmetro de coleto (Figura 2), assim como no trabalho de Campos et al. (2010) onde o diâmetro caulinar aumenta com a reposição de água. Este desempenho também foi observado para plantas de algodão, as quais apresentaram maior diâmetro da base do caule quando cultivadas com maiores quantidade de água (100\% do VTP) (BALDO et al., 2009). O maior diâmetro do coleto pode estar relacionado com a produção de etileno, pois quando há excesso de água este hormônio é produzido em maior quantidade, o que leva ao menor crescimento da raiz principal, e consequentemente o aumento de raízes laterais e axilares, bem como o aumento do diâmetro de coleto. O diâmetro do caule é uma característica importante no girassol, pois diminui o acamamento da cultura e facilita seu manejo, tratos culturais e colheita (BISCARO et al., 2008).

Estes resultados são semelhantes aos conseguidos por Nezami et al. (2008), que verificaram redução de 20 a 46\% no diâmetro do coleto de plantas de girassol em déficit hídrico. As plantas do tratamento $60 \%$ da CRA alcançaram apenas a metade do diâmetro de coleto das plantas do tratamento $80 \%$ da CRA (Figura 2).

Figura 2. Diâmetro do caule de plantas de girassol em diferentes níveis de capacidade de retenção de água (CRA), em casa de vegetação, durante o estádio fenológico V6 ao R4.

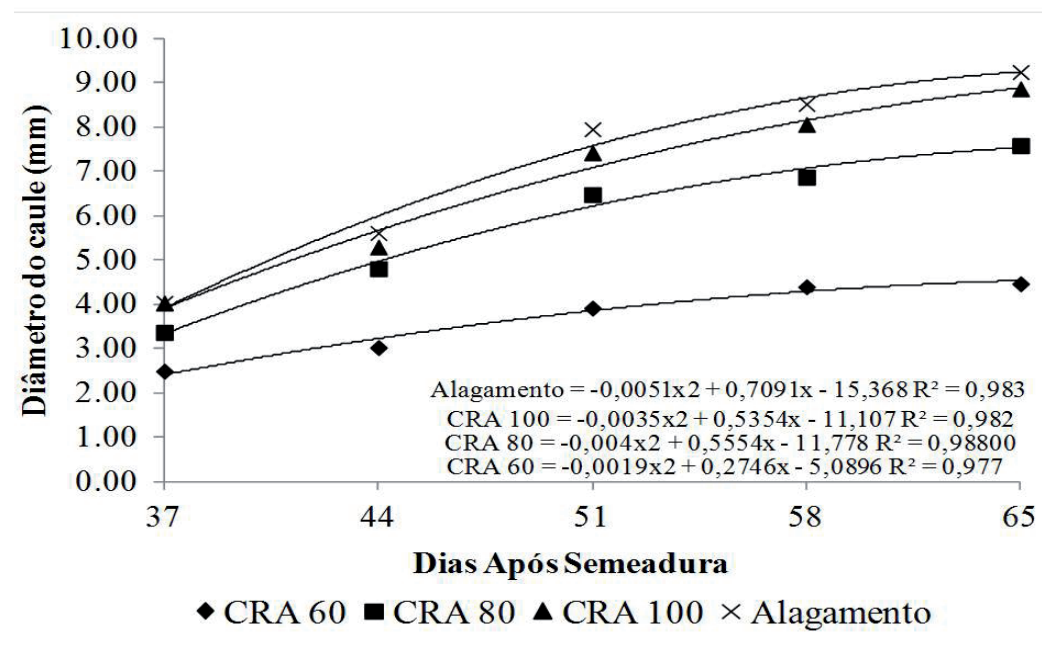

Fonte: Elaboração dos autores. 
O teor de clorofila das folhas de plantas de girassol conduzidas com $60 \%$ da CRA não variou ao longo das avaliações. Possivelmente, a baixa disponibilidade de água limitou a síntese de clorofila. Os demais tratamentos apresentaram maior valor de teor de clorofila por um período. Contudo, nas últimas avaliações houve redução destes valores até abaixo do tratamento $60 \%$ da CRA. Provavelmente, os elevados níveis de água começaram a provocar o aumento da senescência foliar, por elevar a concentração do ABA e etileno, induzindo ao aumento da clorose devido à degradação da clorofila, fato este que pode ser comprovado observandose a curva do tratamento em condição de hipoxia, onde verificou-se menores níveis de clorofila em comparação aos demais tratamentos (Figura 3).

Figura 3. Teor de clorofila de plantas de girassol em diferentes níveis de capacidade de retenção de água (CRA), em casa de vegetação, durante o estádio fenológico V6 ao R4.

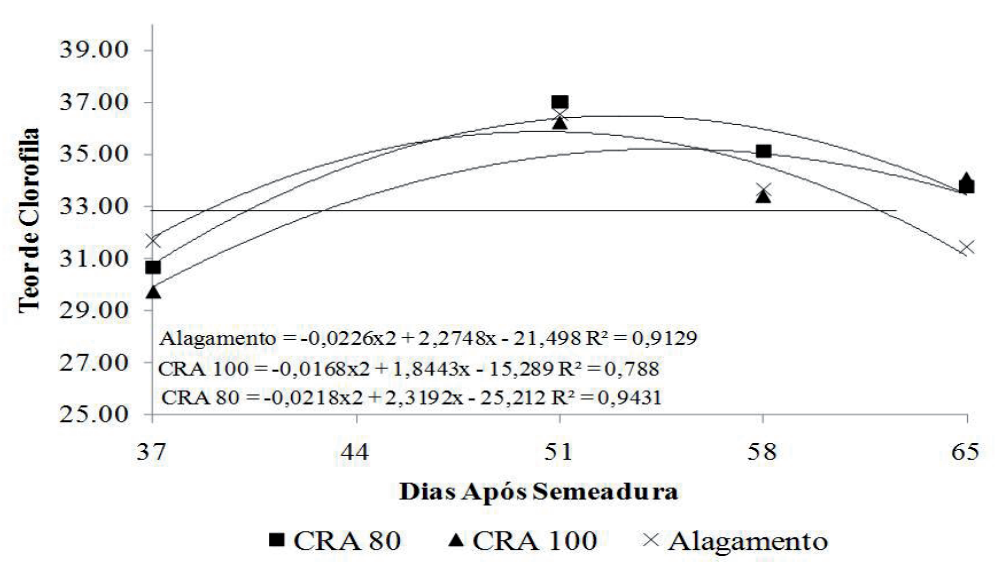

Fonte: Elaboração dos autores.

Os valores de clorofila são menores em plantas cultivadas em solo com maior quantidade de água devido ao aumento da concentração de radicais livres que a destroem (DREW, 1997). A disfunção hormonal, principalmente ligada ao aumento da concentração de etileno nas folhas induz além da perda de clorofila, a senescência (TAIZ; ZEIGER, 2009) e também redução na absorção de nutrientes, principalmente o nitrogênio, que faz parte da molécula de clorofila (LENHARD, 2008). Segundo Taiz e Zeiger (2009) o oxigênio é parte essencial da respiração celular, sendo que neste processo originase o ATP para os processos bioquímicos da raiz. $\mathrm{Na}$ falta desta molécula ocorre redução na atividade de absorção ativa de nutrientes e água, com isso, a parte aérea sofre deficiência de nutrientes necessários ao crescimento. Além disso, a atividade da enzima nitrato redutase é menor em solo alagado (DREW, 1997).

O tratamento $60 \%$ CRA afetou a produção de biomassa, tanto da parte aérea como da raiz. A redução foi maior para MSPA, MSF, MSC e MSR sendo de aproximadamente $300 \%$ em relação ao tratamento $80 \%$ CRA (Figura 4), pois, a falta de água pode levar a redução da expansão celular, fechamento de estômatos, redução na fotossíntese, afetando severamente a produção de biomassa da parte aérea e raiz (TAIZ; ZEIGER, 2009). 
Figura 4. Matéria seca de folhas, caule e raiz de plantas de girassol em diferentes níveis de capacidade de retenção de água (CRA), em casa de vegetação, durante o estádio fenológico V6 ao R4.
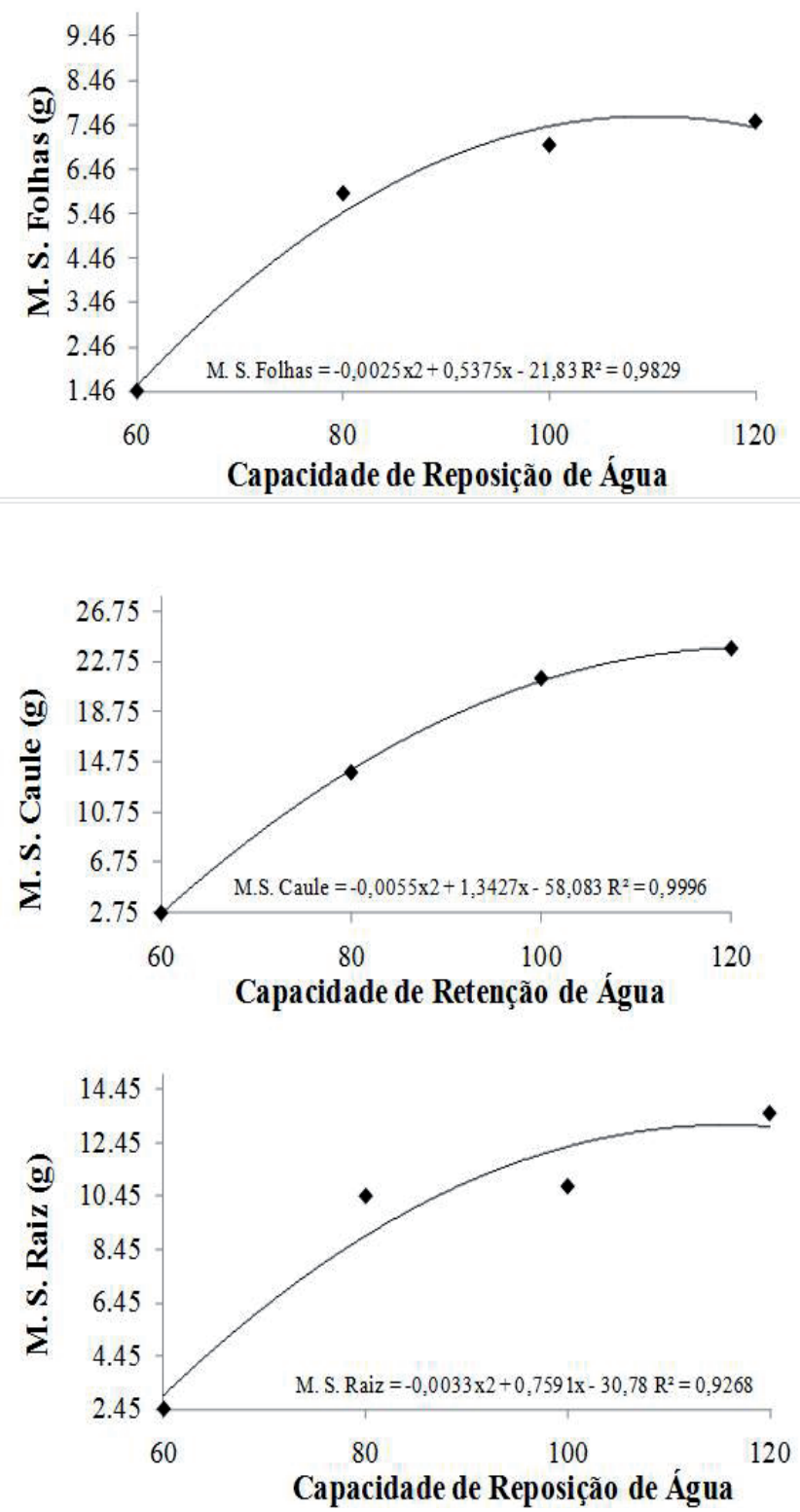

Fonte: Elaboração dos autores.

$\mathrm{Na}$ literatura, alguns trabalhos mostram resultados semelhantes aos desse estudo. Nobre et al. (2010), obtiveram crescimento linear da fitomassa seca da parte aérea do girassol, com o aumento da lâmina de irrigação, com aumento de $280,88 \%$ em comparação ao tratamento em condição de hipoxia e $40 \%$ de necessidade hídrica. Castro et al. (2006) encontraram alta redução de massa seca total para plantas em estresse hídrico (falta de água) comparada com plantas sem estresse hídrico, porém Silva et al. (2007) alcançaram maior biomassa para os maiores níveis de água.

O fornecimento de água em quantidades ideais e bem distribuídas durante o ciclo da planta é essencial, podendo ser até $90 \%$ da massa fresca das plantas. Esta regularidade assume papel importante 
no metabolismo vegetal, participando de várias reações fundamentais para o transporte de seiva na planta, também atuando como protetor térmico (TAIZ; ZEIGER, 2004). É importante lembrar que o excesso de água também é prejudicial. Letey, Stolzi e Blank. (1962) verificaram redução no crescimento de raízes e parte aérea de girassol cultivado em solo sob condição de hipoxia.

A relação entre massa seca da raiz e da parte aérea foi maior no tratamento $60 \%$ CRA, o que está de acordo com Taiz e Zeiger (2009). Segundo Sharp (2002) o nível de ABA aumenta em plantas estressadas por falta de água e acredita-se que este hormônio possa diminuir a relação raiz/parte aérea, devido ao estímulo do crescimento da raiz, redução na síntese do etileno, diminuição do crescimento do caule e aumento na abscisão foliar. Esse fato pode estar relacionado a um mecanismo de tolerância ao estresse hídrico, pois, ocorre priorização do crescimento das raízes, proporcionando maior capacidade de absorver água e nutrientes (CORREIA; NOGUEIRA, 2004). Lenhard (2008), estudando crescimento inicial de mudas de "pau ferro" (Caesalpinia ferrea) sob teores de água de 12,$5 ; 40 ; 70 \%$ da CRA e alagamento, também verificaram maior relação raiz/parte aérea nas plantas cultivadas sob menores quantidades de água.

As plantas submetidas a maiores teores de água produziram um maior número de folhas e por consequência aumento da área foliar (Figura 5), o que está em conformidade com os resultados de Campos et al. (2010), onde houve aumento do número de folhas de girassol até aos 40 dias após germinação. A interpretação dos resultados dos trabalhos de Soriano et al. (2004), mostra que as plantas de girassol sob condição de irrigação apresentaram índices de área foliar maiores do que os obtidos sob limitação de água. A expansão foliar é muito sensível à deficiência hídrica, podendo ser completamente inibida sob níveis moderados de estresse (BOYER, 1970). A menor disponibilidade de água no solo provoca redução na em sua absorção e com isso, as células das plantas tem menor pressão de turgor, levando a menor expansão (TAIZ; ZEIGER, 2009).

Figura 5. Área foliar e número de folhas de girassol em diferentes níveis de capacidade de retenção de água (CRA), em casa de vegetação, durante o estádio fenológico V6 ao R4.

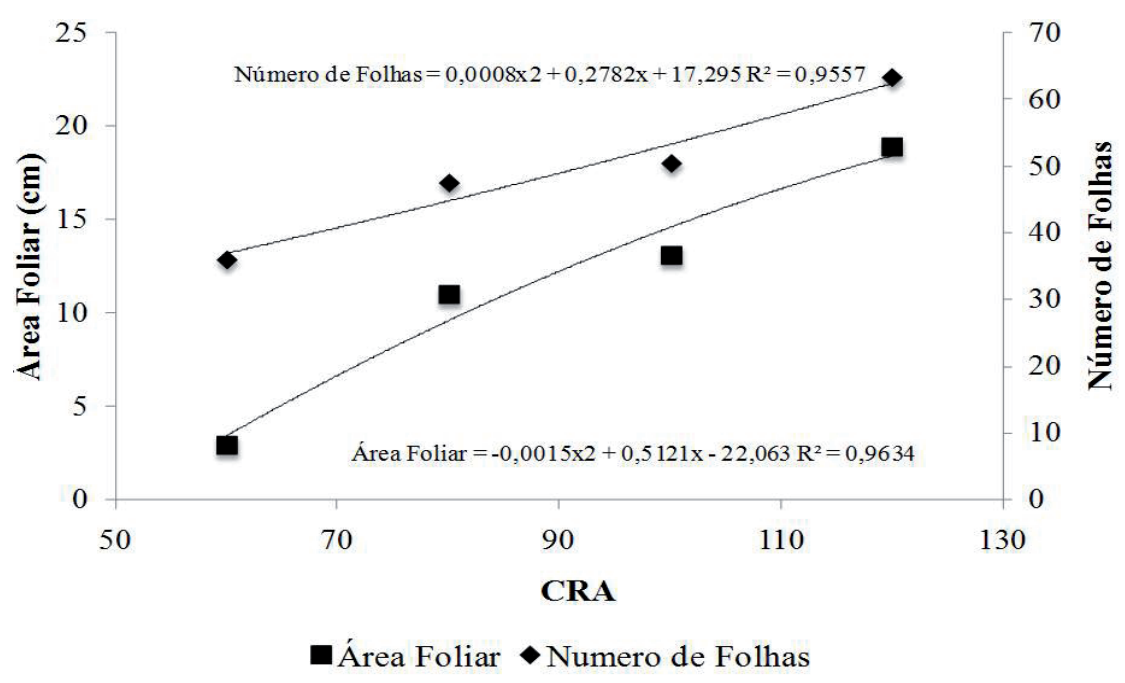

Fonte: Elaboração dos autores. 


\section{Conclusão}

O cultivo do girassol EMBRAPA 122/V-2000 com $60 \%$ da CRA proporcionou redução em todos os parâmetros morfológicos avaliados, de modo que o melhor desempenho destes foi obtido em condições de disponibilidade hídrica de 80 a $100 \%$ da capacidade de retenção de água.

\section{Referências}

ACOSTA, J. F. Consumo hídrico da cultura do girassol irrigada na região da Chapada do Apodi - RN. 2009. Dissertação (Mestrado em Meteorologia) - Universidade Federal de Campina Grande, Centro de Tecnologia e Recursos Naturais, Campina Grande.

AMORIMNETO,M.daS.; GOMIDE, R.L.; SEDIYAMA, G. C. Índice de estresse hídrico da cultura do feijoeiro irrigado. Revista Brasileira de Agrometeorologia, Santa Maria, v. 4, n. 1, p. 49-53, 1996.

BALDO, R.; SCALON, S. P. Q.; ROSA, Y. B. C. J.; MUSSURY, R. M.; BETONI, R.; BARRETO, W. S. Comportamento do algodoeiro cultivar delta opal sob estresse hídrico com e sem aplicação de bioestimulante. Ciência e Agrotecnologia, Lavras, v. 33, p. 1804-1812, 2009.

BISCARO, G. A.; MACHADO, J. R.; TOSTA, M. da S.; MENDONÇA, V.; SORATTO, R. P.; CARVALHO, L. A. Adubação nitrogenada em cobertura no girassol irrigado nas condições de Cassilândia - MS. Ciência e Agrotecnologia, Lavras, v. 32, n. 5, p. 1366-1373, 2008.

BOYER, J. S. Leaf enlargement and metabolic rates in corn, soybean, and sunflower at various leaf water potentials. Plant Physiology, Illinois, v. 46, n. 2, p. 233235, 1970.

BREMMER, P. M.; PRESTON, G. K.; GROTH, C. F. A field comparison of sunflower (Helianthus annuиs L.) and sorghum (Sorghum bicolor) in a long drying cycle. In: Water extraction. Australian Journal of Agricultural Research, Cairo, v. 37, n. 5, p. 483-493, 1986.

CAMPOS, V. B.; CHAVES, L. H. G.; GUEDES FILHO, D. H.; SANTOS JÚNIOR, J. A. Reposição da água de irrigação na cultura do girassol Embrapa 122/v-2000. In: FERTIBIO, 2010, Viçosa. Anais eletrônicos... Viçosa: SBCS, 2010. Disponível em: <http://74.125.155.132/ scholar?q=cache:c4fDWrJAi7QJ: scholar.google.com/ $+\mathrm{r}$ eposi $\% \mathrm{C} 3 \% \mathrm{~A} 7 \% \mathrm{C} 3 \% \mathrm{~A} 3 \mathrm{o}+$ da + agua + de + irriga $\% \mathrm{C} 3 \% \mathrm{~A}$ $7 \% \mathrm{C} 3 \% \mathrm{~A} 3 \mathrm{o}+$ na + cultura + do + girassol $+\& \mathrm{hl}=$ pt-BR\&as sdt $=0 \&$ as_vis $=1>$. Acesso em: 20 fev. 2010 .
CARTER, J. F. Sunflower science and technology. Madison: American Society of Agronomy, 1978. 505 p.

CASTRO, C.; MOREIRA, A.; OLIVEIRA, R. F.; DECHEN, A. R. Boro e estresse hídrico na produçao do girassol. Ciência e Agrotecnologia, Lavras, v. 30, n. 2, p. 214-220, 2006.

CORREIA, K. G.; NOGUEIRA, R. J. M. C. Avaliação do crescimento de amendoim (Arachis hypogaea L.) submetido ao déficit hídrico. Revista de Biologia e Ciências da Terra, Campina Grande, v. 4, n. 2, p. 1-7, 2004.

DREW, M. C. Oxygen deficiency and root metabolism: injury and acclimation under hypoxia and anoxia. Annual Review of Plant Physiology and Plant Molecular Biology, Palo Alto, v. 48, p. 223-250, 1997.

EMPRESA BRASILEIRA DE PESQUISA AGROPECUÁRIA - EMBRAPA CNPSo. Sistema de produção: girassol. Londrina: EMBRAPA CNPSo, 2000. Disponível em: <http://www.cnpso.embrapa.br/ producaogirassol/index.htm>. Acesso em: 27 jun. 2010.

FAO. Crop water management. Sunflower. 2002. Disponível em: <http://www.fao.org/ag/agl/aglw/ cropwater/sunflower.stm>. Acesso em: 23 jun. 2010.

FERREIRA, D. F. SISVAR - sistema de análise de variância. Versão 3.04. Lavras: UFLA, 2000.

KERBAUY, G. B. Fisiologia vegetal. Guanabara: Koogan, 2004. 439 p.

LEITE, R. M. V. B. C.; BRIGHENTI, A. M.; CASTRO, C. Girassol no Brasil. Londrina: Embrapa Soja, 2005. $641 \mathrm{p}$.

LENHARD, N. R. Crescimento inicial de Caesalpinia ferrae ex. Tul. Var. Leiostachya Benth Caesalpinaseae (Pau-Ferro) sob diferentes regimes hídricos e sombreamento. 2008. Dissertação (Mestrado em Produção Vegetal) - Universidade Federal da Grande Dourados, Dourados.

LETEY, J.; STOLZI, H.; BLANK, G. B. Effect of duration of timing of low soil oxygen content on shoot and root growth. Agronomy Journal, Madson, v. 54, n. 1, p. 34-37, 1962.

NEZAMI, A.; KHAZAEI, H. R.; BOROUMAND REZAZADEH, Z.; HOSSEINI, A. Effects of drought stress and defoliation on sunflower (Helianthus annuus) in controlled conditions. Desert, Tehran, v. 1, p. 99-104, 2008 . 
NOBRE, R. G.; GHEYI, H. R.; SOARES, F. A. L.; ANDRADE, L. O.; NASCIMENTO, E. C. S. Produção do girassol sob diferentes lâminas com efluentes domésticos e adubação orgânica. Revista Brasileira de Engenharia Agrícola e Ambiental, Campina Grande, v. 14, n. 7, p. 747-754, 2010.

SFREDO, G. J.; CAMPOS, R. J.; SARRUGE, J. R. Girassol: nutrição mineral e adubação. Londrina: Embrapa CNPSo, 1984. 36 p.

SHARP, R. E. Interaction with ethylene: changing views on the role of abscisic acid in root and shoot growth responses to water stress. Plant Cell Environment, Columbia, v. 25, n. 2, p. 211-222, 2002.
SILVA, M. L. O.; FARIA, M. A.; MORAIS, A. R.; ANDRADE, G. P.; LIMA, E. M. C. Crescimento e produtividade do girassol cultivado na entressafra com diferentes lâminas de água. Revista Brasileira de Engenharia Agrícola e Ambiental, Campina Grande, v. 11, n. 5, p. 482-488, 2007.

SORIANO, M. A. F.; ORGAZ, F. J.; VILLALOBOS, J. F.; FERERES, E. Efficiency of water use of early plantings of sunflower. European Journal of Agronomy, Córdoba, v. 21, n. 4, p. 465-476, 2004.

TAIZ, L.; ZEIGER, E. Fisiologia vegetal. 3. ed. Porto Alegre: Artmed, 2004. 613 p.

4. ed. Porto Alegre: Armed, 2009. 848 p. 
